\title{
ISOTOPE SELECTIVE DETECTION OF NITRIC OXIDE IN HUMAN EXHALATION
}

\author{
J. LAUENSTEIN AND K.-H. GERICKE \\ Institut für Physikalische und Theoretische Chemie, \\ Technische Universität Braunschweig, \\ Hans-Sommer-Straße 10, D-38106 Braunschweig, Germany
}

\section{Introduction}

Nitric oxide, NO, is a molecule with several different attributes. It interacts toxically with the human body 1 and plays an important role in atmospheric chemistry $2 \mathrm{~b}$ No generated by combustion processe 4 catalytically increases the decay of the ozone layer in the stratosphere 5 Since R. F. Furchgott, L. J. Ignarro and F. Merid were awarded the Nobel Prize for medicine in 1998, the number of scientists studying NO is constantly increasing. Today, the important role of nitric oxide in humans, animals and plants is well established. The main problem when investigating the effects of NO in the human body is to detect it accurately, because its lifetime in the human body is very short due to its reactivity 6 Ideally, a method is needed to measure NO non-invasively. If these goals can be achieved, NO can be detected in human breath, which is normally at a concentration of about 10 parts per billion (ppb) 7 These low concentrations require an extremely sensitive technique which should also be selective, accurate and rapid. To achieve this, one photon laser induced fluorescence (LIF) is used. In this paper the detection of NO in exhaled human breath using LIF is described.

\section{Theory}

The ground state of nitric oxide has the configuration $\mathrm{X}^{2} \Pi$, which is split into ${ }^{2} \Pi_{1 / 2}$ and ${ }^{2} \Pi_{3 / 2}$ states. Figure 1 illustrates a simulated absorption spectrum of NO that contains the $\gamma$-band $(\mathrm{A} \leftarrow \mathrm{X}), \beta$-band $(\mathrm{B} \leftarrow \mathrm{X}), \delta$-band $(\mathrm{C} \leftarrow \mathrm{X})$ and $\varepsilon$-band $(\mathrm{D} \leftarrow \mathrm{X})$. The spectrum is simulated by LifBase 8 and does not contain all possible transitions. In these experiments, the molecule is excited in the $\gamma(0,0)$-band around $226 \mathrm{~nm}$. From the $\gamma$ state the molecule 
relaxes by emitting a photon. This fluorescence can be measured by a photomultiplier tube. The possible transitions and resulting branches are presented in Fig. 2. The probabilities of the different fluorescence transitions are described by the appropriate Franck-Condon factors 90 For detection, the $(0,2)$ transition occurring at $247.4 \mathrm{~nm}$ was chosen because of the relatively high Franck-Condon factor and the possibility to filter out scattered light around $226 \mathrm{~nm}$.

Nitrogen and oxygen atoms have the following stable isotope distributions: ${ }^{14} \mathrm{~N}(99.63 \%),{ }^{15} \mathrm{~N}(0.37 \%),{ }^{16} \mathrm{O}(99.76 \%),{ }^{17} \mathrm{O}(0.04 \%),{ }^{18} \mathrm{O}$ $(0.20 \%)$. The possible combinations of nitrogen and oxygen in $\mathrm{NO}$ are: ${ }^{14} \mathrm{~N}^{16} \mathrm{O}(99.390888 \%),{ }^{15} \mathrm{~N}^{16} \mathrm{O}(0.369112 \%),{ }^{14} \mathrm{~N}^{18} \mathrm{O}(0.19926 \%),{ }^{14} \mathrm{~N}^{17} \mathrm{O}$ $(0.039852 \%),{ }^{15} \mathrm{~N}^{18} \mathrm{O}(0.00074 \%)$ and ${ }^{15} \mathrm{~N}^{17} \mathrm{O}(0.000148 \%)$. In that which follows, only on the two most frequently occurring isotopomers ${ }^{14} \mathrm{~N}^{18} \mathrm{O}$ and ${ }^{15} \mathrm{~N}^{18} \mathrm{O}$ are considered. The spectra of these isotopomeres are slightly different due to their differing reduced masses; therefore, it is possible to detect both isotopomers with the same optical setup, but according to the natural abundances the ${ }^{14} \mathrm{NO}$ absorption is about 270 -fold greater than the ${ }^{15} \mathrm{NO}$ absorption. So a spectral region must be chosen where only ${ }^{15} \mathrm{NO}$ absorbs the laser radiation, taking into account spectral laser linewidth and

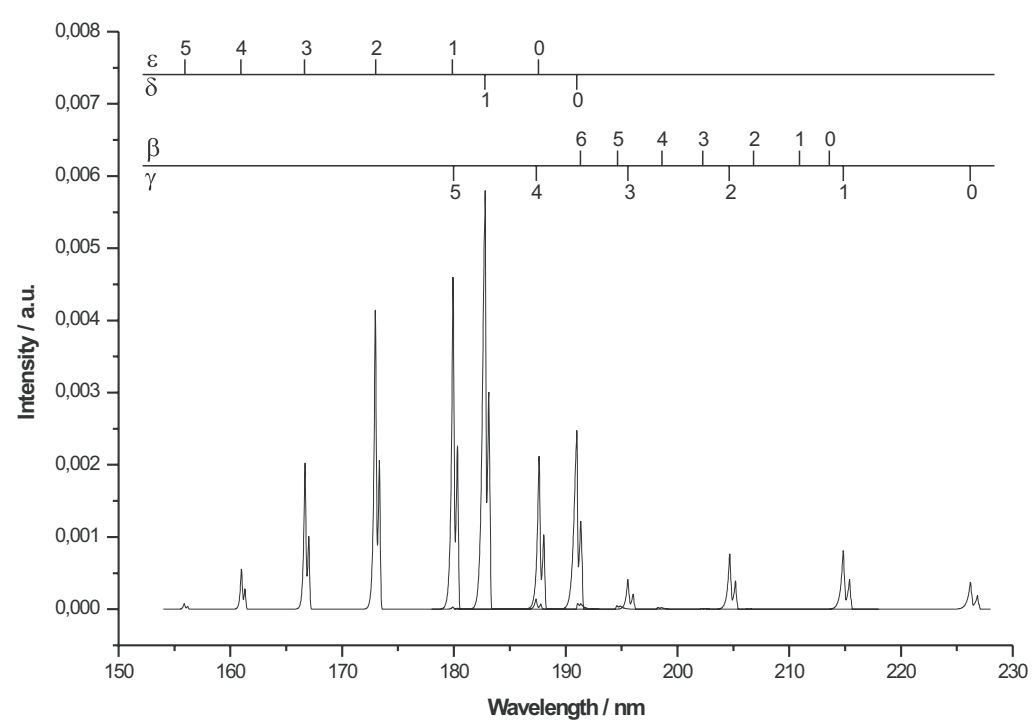

Fig. 1. Simulated absorption spectrum of nitric oxide in the ultraviolet region. Not all possible transitions are displayed 
Doppler broadening of the peaks. For this purpose the absorption spectra of ${ }^{14} \mathrm{NO}$ and ${ }^{15} \mathrm{NO}$ is simulated. One candidate for ${ }^{15} \mathrm{NO}$ detection is the spectral region between $226.369 \mathrm{~nm}$ and $226.387 \mathrm{~nm}$ that contains four peaks: $P_{11}(6.5 ; 11.5) / R_{22}(10.5), P_{11}(7.5 ; 10.5), \quad Q_{22}(15.5) / R_{12}(15.5)$ and $P_{11}(8.5 ; 9.5)$. The $Q_{22}(15.5) / R_{12}(15.5)$ transition is not resolved by LIF due to the weak transition probability and the closeness to the $P_{11}(7.5 ; 10.5)$

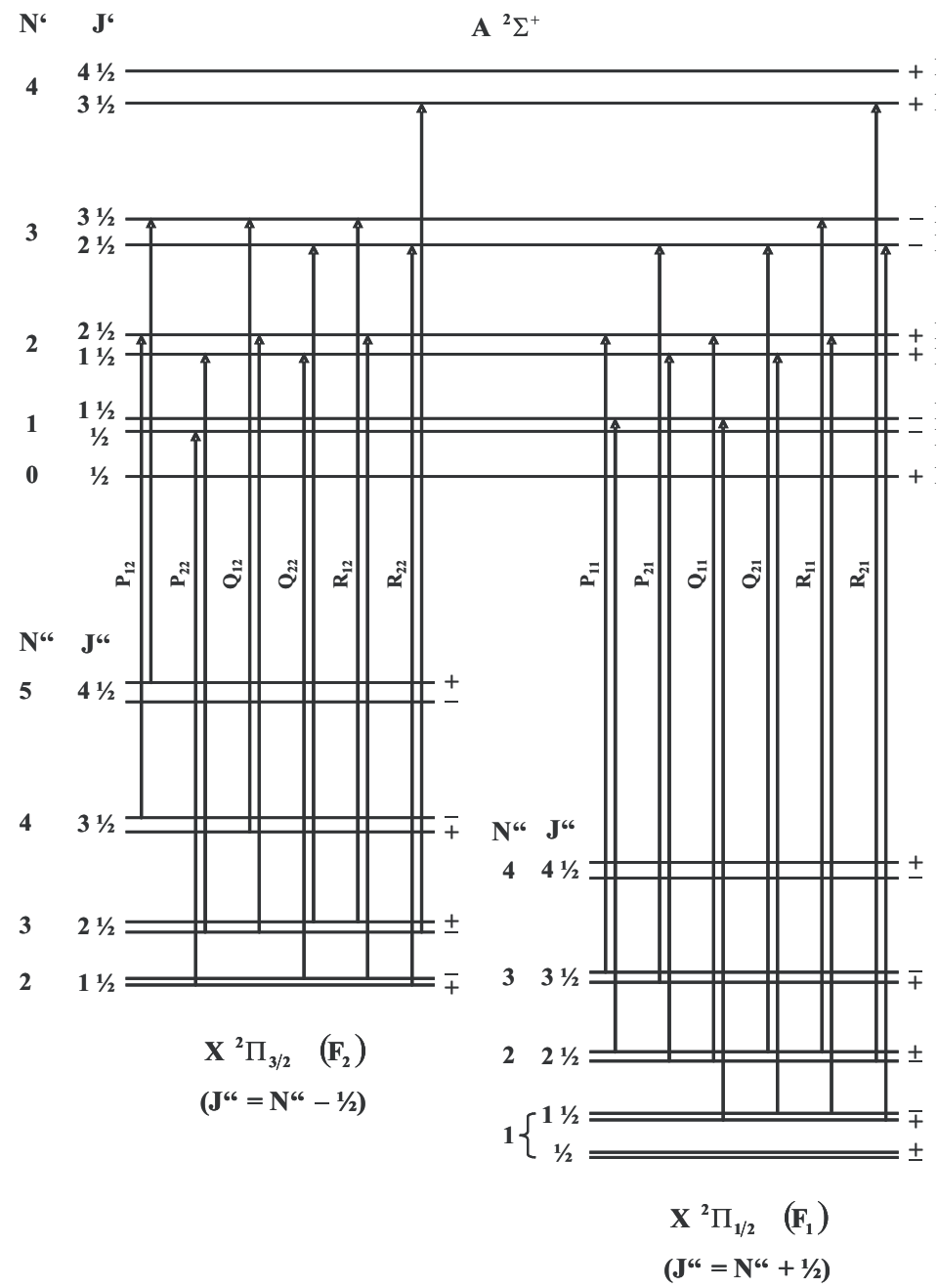

Fig. 2. Energy level diagram of the $\mathrm{A}^{2} \Sigma^{+} \leftarrow \mathrm{X}^{2} \Pi$ transition of nitric oxide 


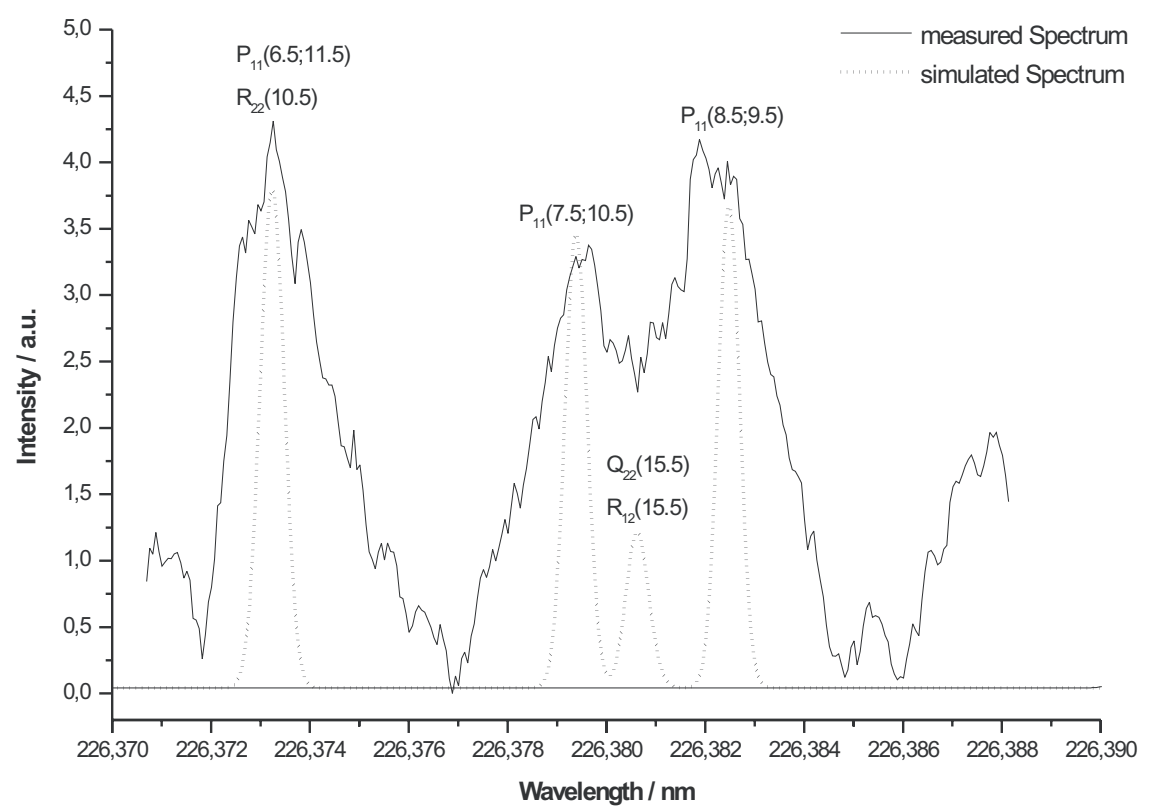

Fig. 3. Comparison of measured and simulated ${ }^{15} \mathrm{NO}$ spectra. The additional broadening of the experimental line is due to the linewidth of the dye laser radiation.

transition. Fig. 3 illustrates this region with the four ${ }^{15} \mathrm{NO}$ transitions in more detail. It contains a simulated and a measured spectrum. The peak width is due to Doppler broadening and the linewidth of the laser radiation. A spectral width of less than $2 \mathrm{~cm}^{-1}$ is required to detect ${ }^{15} \mathrm{NO}$, because of the surrounding ${ }^{14} \mathrm{NO}$ peaks that conceal the ${ }^{15} \mathrm{NO}$ peaks at broader linewidth. In addition, the pulse length should be short compared to the fluorescence lifetime in order to discriminate between the excitation light and the fluorescence using appropriate gating techniques 11

The maximum fluorescence intensity is obtained at a pressure of 10 mbar, because quenching interferes at higher pressure $\$ 12 \|_{1} 3$ and too few fluorescing species are produced at lower pressures. The optimal pressure was determined theoretically and experimentally.

\section{Experimental Setup}

Figure 4 presents a schematic drawing of the experimental setup used to detect ${ }^{14} \mathrm{NO}$ and ${ }^{15} \mathrm{NO}$. A XeCl-excimer laser (Lambda Physik LPX600) pumps a dye laser (Lambda Physik LPD2000) that was operated by Couma- 
rine 4714 The laser beam was frequency doubled by a BBO crystal to generate UV radiation between $225 \mathrm{~nm}$ and $227 \mathrm{~nm}$. The maximum energy of the resulting ultraviolet radiation was $800 \mu \mathrm{J}$ at a pulse width of $0.2 \mathrm{~cm}^{-1}$ and a repetition rate of $5 \mathrm{~Hz}$. The UV beam was separated from the visible beam by a Pellin Broca prism and then entered the cell through a quartz window at the Brewster angle. After passing through the cell, the laser power is monitored by a joulemeter (Laser Precision Corp., Model RJP-735). The detection optics were arranged perpendicular to the beam axis: two $f / 1$ lenses focus the fluorescence to the photomultiplier tube (Hamamatsu R3788), whereas between the two lenses, a bandpass filter blocks the scattered light. The filter (Andover Corporation, 248FS10-50) had a centre wavelength at $248 \pm 3 \mathrm{~nm}$ with a transmission of $17 \%$. The signals of the photomultiplier and the joulemeter were integrated by a gated integrator and boxcar averager (Stanford Research Systems SR250, SR280), transferred to a personal computer via an I/O controller card (National Instruments DAQ PCI-1200) and acquired by LabView 5.0. The resulting data were analysed by Origin.

The sample gas mixtures were formed from pure nitrogen (6.0, Linde) and an $\mathrm{NO} / \mathrm{N}_{2}$ mixture (2.5 ppm $\pm 5 \%$, Westfalen) using two mass flow controllers (MKS 1179). The total gas flow was established at $100 \mathrm{sccm}$, while the pressure in the chamber was automatically maintained at 10 mbar via an automatic valve and a pressure gauge (MKS 248AC/221A). The system was evacuated by a rotary vane pump (Edwards RV12) with a cryotrap arranged in line to prevent oil particles reaching the cell which can be fragmented by the laser radiation.

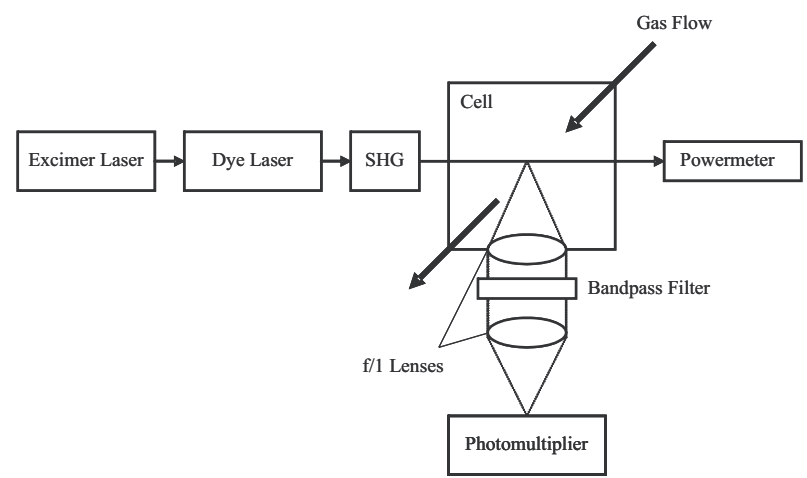

Fig. 4. Schematic view of the experimental setup 


\section{Results}

Since LIF is not an absolute method, the system has to be calibrated using known NO concentrations. Different ${ }^{14} \mathrm{NO}$ and ${ }^{15} \mathrm{NO}$ concentrations were produced by mixing the $2.5 \mathrm{ppm}$ NO test gas with pure nitrogen via the mass flow controllers. The results are illustrated in Fig. 5. Using these calibration curves, ${ }^{14} \mathrm{NO}$ and ${ }^{15} \mathrm{NO}$ concentrations in a sample could be determined performing only one calibration exercise each day. To measure low NO isotopomer concentrations very accurately, the standard addition method was used 15 Thus, known NO isotopomer concentrations were added to the sample and the resulting signal intensity was monitored. The resulting straight line is fitted and extrapolated to the abscissa; the intercept (see Fig. 6] provides the absolute value of the concentration of NO isotopomer in the sample. The advantages of the standard addition method are the very high accuracy due to signal averaging and the independence on laser power, photo-multiplier voltage and boxcar sensitivity, as long as these parameters remain constant during the measurement.

To demonstrate the validity of this NO detection system, tracer experiments were performed using ${ }^{15} \mathrm{~N}$-labelled arginine. L-arginine is known to be the precursor for nitric oxide in the human body 16 so $7.5 \mathrm{mg} / \mathrm{kg}$ body weight of ${ }^{15} \mathrm{~N}$-labelled L-arginine were administered orally to a male and a female volunteer. $95 \%$ of the nitrogen atoms were ${ }^{15} \mathrm{~N}$. The time

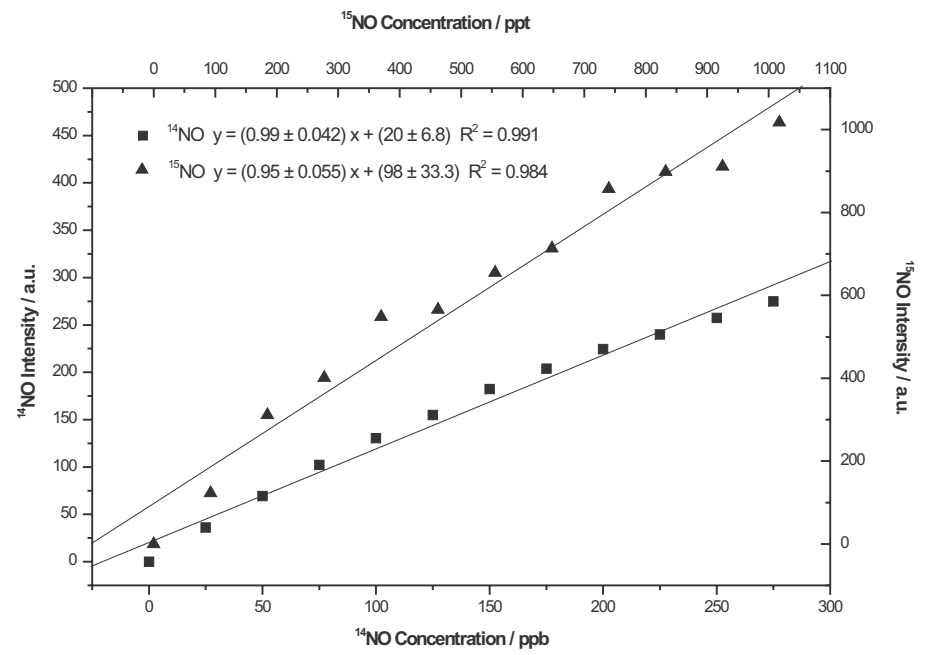

Fig. 5. Calibration curves for ${ }^{14} \mathrm{NO}$ and ${ }^{15} \mathrm{NO}$ 
dependence of the ${ }^{15} \mathrm{NO}$ content of the exhaled air was monitored. The volunteers blew up sample bags made of polyvinyl fluoride (PVF) which were coupled to the mass flow system. The results are shown in Fig. 7. Both volunteers were healthy non-smokers and filled the sample bags in one breath exhalation. The male was 59 years old, the female 23 years old.

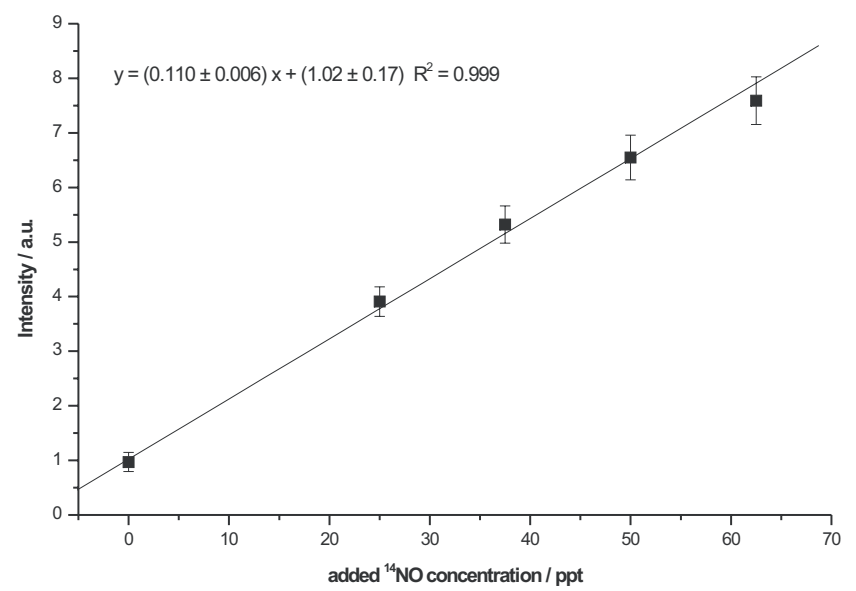

Fig. 6. Measurement of ${ }^{14} \mathrm{NO}$ via the standard addition method. The ${ }^{14} \mathrm{NO}$ content of the sample is $9.3 \mathrm{ppb} \pm 0.2 \mathrm{ppb}$.

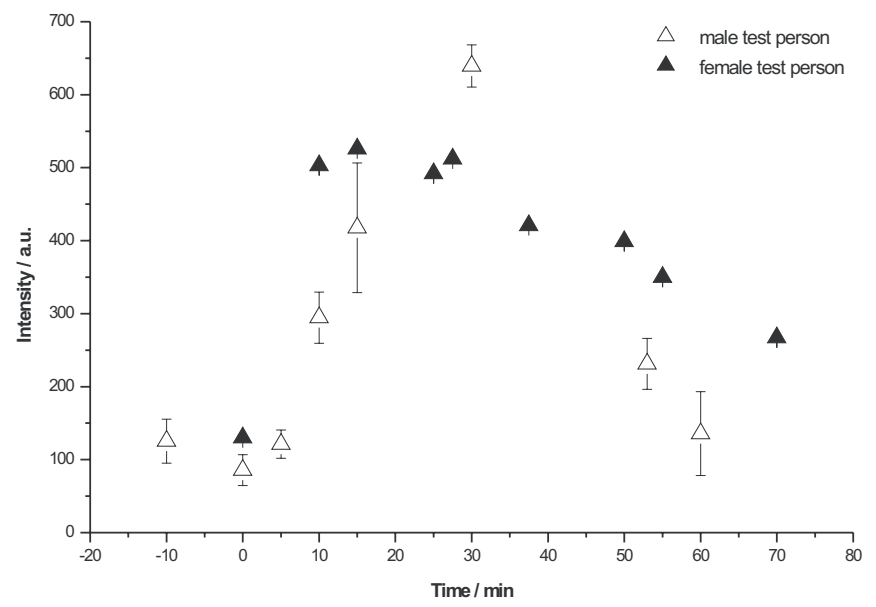

Fig. 7. Monitoring the ${ }^{15} \mathrm{NO}$ concentration in exhaled breath after ingestion of ${ }^{15} \mathrm{~N}$-labelled arginine. Time zero characterises the moment of intake. 
Surprisingly, the amount of ${ }^{15} \mathrm{NO}$ increases rapidly following ingestion. The maximum concentration is reached after 10 minutes and falls back to normal levels after about one hour. The experiments with the male volunteer were not performed using the standard addition method; therefore the uncertainties are much higher compared to those for the female volunteer, which are less than $1 \%$. Currently, the practical detection limit of the apparatus is better than $1 \mathrm{ppt}$, but this is expected to be reduced to below $0.1 \mathrm{ppt}$.

\section{Conclusions}

Our results demonstrate that LIF is a reliable method for measuring nitric oxide traces in gas samples with respect to sensitivity, selectivity, accuracy and time resolution. The sensitivity and selectivity is sufficiently high to detect different isotopomers of nitric oxide down to sub-ppt levels. Hence, experiments using isotopically labelled NO precursor compounds can be carried out to investigate the generation of NO in the body. The high time resolution enables online measurements of nitric oxide in human breath just as in animal breath, $\frac{17}{17}$ plant and soil emissions, $\frac{18 \| 1}{119}$ and combustion exhaust gases $\frac{9}{\square}$

\section{References}

1. Hess D. Adverse effects and toxicity of inhaled nitric oxide. Respir Care 1999; 44: 315-329.

2. Bloss W, Gravestock T, Heard D, Ingham T, Johnson G, Lee J. Application of a compact all solid-state laser system to the in situ detection of atmospheric $\mathrm{OH}, \mathrm{HO}_{2}, \mathrm{NO}$ and $\mathrm{IO}$ by laser-induced fluorescence. J Environ Monit 2003; 5: 21-28.

3. Bradshaw J, Rodgers M, Davis D. Single photon laser-induced fluorescence detection of $\mathrm{NO}$ and $\mathrm{SO}_{2}$ for atmospheric conditions of composition and pressure. Appl Opt 1982; 21: 2493-2500.

4. Reisel J, Laurendeau N. Quantitative LIF measurements and modeling of nitric oxide in high-pressure $\mathrm{C}_{2} \mathrm{H}_{4} / \mathrm{O}_{2} / \mathrm{N}_{2}$ flames. Combust Flames 1995; 101: 141-152.

5. Birks J, Shoemaker B, Leck T, Hinton D. Studies of reactions of importance in the stratosphere. I. Reaction of nitric oxide with ozone. J Chem Phys 1976; 65: 5181-5185.

6. Thomas D, Liu X, Kantrow S, Lancaster JJ. The biological lifetime of nitric oxide: implications for the perivascular dynamics of $\mathrm{NO}$ and $\mathrm{O}_{2}$. Proc Nat Acad Scienc USA 2001; 98: 355-360. 
7. Robinson J, Bollinger M, Birks J. Luminol $/ \mathrm{H}_{2} \mathrm{O}_{2}$ chemiluminescence detector for the analysis of nitric oxide in exhaled breath. Anal Chem 1999; 22: 5131-5136.

8. Luque J, Crosley D. LIFBASE: Database and spectral simulation (version 1.5). SRI International Report MP 99-009, 1999.

9. Spindler RJ, Isaacson L, Wentink TJ. Franck-Condon factors and $r$-centroids for the gamma system of NO. J Quant Spectrosc Radiat Transfer 1970; 10: 621-628.

10. Luque J, Crosley D. Transition probabilities and electronic transition moments of the $\mathrm{A}^{2} \Sigma^{+} \leftarrow \mathrm{X}^{2} \Pi$ and $\mathrm{D}^{2} \Sigma^{+} \leftarrow \mathrm{X}^{2} \Pi$ systems of nitric oxide. $J$ Chem Phys 1999; 111: 7405-7415.

11. Huber K, Herzberg G. Molecular spectra and molecular structure IV: Constants of diatomic molecules. New York: Van Nostrand Reinhold, 1979.

12. McDermid I, Laudenslager J. Radiative lifetimes and electronic quenching rate constants for single-photon-excited rotational levels of $\mathrm{NO}\left(\mathrm{A}^{2} \Sigma^{+}\right.$, $\left.v^{\prime}=0\right)$. J Quant Spectrosc Radiat Transfer 1982; 27: 483-492.

13. Paul P, Gray J, Durant JJ, Thoman JJ. Collisional electronic quenching rates for $\mathrm{NO} \mathrm{A}{ }^{2} \Sigma^{+}\left(v^{\prime}=0\right)$. Chem Phys Lett 1996; 259: 508-514.

14. Brackmann U. Lambdachrome Laser Dyes. Goettingen: Lambda Physik, 1997.

15. Ingle JJ, Crouc S. Spectrochemical analysis. New Jersey: Prentice-Hall, 1988.

16. Schmidt HH, Klein MM, Niroomand F, Bohme E. Is arginine a physiological precursor of endothelium-derived nitric oxide? Eur J Pharmacol 1988; 148: 293-295.

17. Marlin DJ, Young LE, McMurphy R, Walsh K, Dixon P. Effect of two anaesthetic regimens on airway nitric oxide production in horses. $\mathrm{Br} J$ Anaesth 2001; 86: 127-130.

18. Rockel P, Strube F, Rockel A, Wildt J, Kaiser WM. Regulation of nitric oxide (NO) production by plant nitrate reductase in vivo and in vitro. J Exp Bot 2002; 53: 103-110.

19. Bollmann A, Koschorreck M, Meuser K, Conrad R. Comparison of two different methods to measure nitric oxide turnover in soils. Biol Fertil Soils 1999; 29: $104-110$. 